Editorial

\title{
Humanities-About Sections
}

\author{
Albrecht Classen \\ Department of German Studies, University of Arizona, Tucson, AZ 85721, USA; aclassen@arizona.edu
}

Received: 28 June 2020; Accepted: 28 June 2020; Published: 30 June 2020

check for updates

What is Humanities Open Access all about? Innovative Perspectives and Inclusivity as the Platform for Novel Approaches in Humanities Research.

Our journal, Humanities Open Access, has tried very hard to be at the cutting edge in the vast field of the Humanities, opening itself up to many different branches, including Literature, Film, Print and Digital Media, Gender, History, Art History, Animal and Plant Studies, and so forth, aiming for many different cross-pollinations in that process. However, all this innovation is possible only if we closely maintain a solid footing in the traditional concepts of the Humanities, broadly defined by focusing on the artistic, literary, or narrative expressions of human concerns, ideals, values, and concepts. We look at the widest range of manifestations of the human mind, and those can and should also include the human body (Medical Humanities), the material environment (Anthropology, Archaeology), and constructions by human beings (Architecture).

Of course, the problem easily emerges when we try to maintain a reasonable, intellectually shared discourse, and the further we move out on this metaphorical limb, the more we are challenged in keeping the core issue of the Humanities in mind, constantly struggling to define those specifically. But literary texts, films, video games, social media, opera, and the visual arts are also studied by anthropologists and archeologists, for instance, and even though the examined data and methodologies can easily differ to some extent, ultimately, our journal welcomes contributions from many of those related fields, including Education, Psychology, Geography, Geology, Sociology, Economics, and Political Sciences, as long as the authors focus on human expressions, experiences, feelings, and needs beyond the purely material dimensions.

There need to be a certain degree of rapprochement of the various disciplines, agreed-upon core values and concepts, so this kind of collaboration represents also a considerable effort at negotiation and compromise. No one suggests that scholars in the Humanities suddenly turn into anthropologists, for instance, and vice versa. However, there always remains a shared focus on the human being, the life of the homo sapiens, as expressed in a myriad of physical and spiritual manifestations. Similarly, scholars of spirituality can easily draw from literary texts or movies in order to pursue the same goal, i.e., probing how to understand this curious creature and its life and death, its desires, efforts, struggles, failures, and triumphs. We look at the relevant context and at the inside of human life, maybe the spiritual essence, expressed in an infinite number of manifestations.

Further, most people live in houses, so we must ask ourselves what kind of spaces those might be and what each architectural style and design says about the human culture; and we ought to wonder how building designs reflect on human culture and social and economic conditions. How do certain literary texts or cinematographic productions, artwork or musical compositions contribute to the understanding of architecture? This question applies also to anthropology and archaeology, to environmental and medical humanists. Hence, we hope that our journal can thus increasingly turn into a global platform where those negotiations among the various disciplines, all combined in the field of Geisteswissenschaften, can take place and come together on the basis of the same fundamental human concern, both from a historical and a modern perspective. By the same token, we do not want to water down the notion of the Humanities as a global Kulturwissenschaft where everything goes as long as it is 
not hard sciences. We live, by now, in the Anthropocene, and in order to figure out a way how we as a human race can cope in these most challenging times during which even our Earth as we know it has become at stake, we do not only need the hard Sciences and Medicine, but very much so also the Humanities so that we can to come to terms with the transcendental aspects deeply determining human existence.

The Humanities are more specifically defined by a non-material perspective, but the insights by archaeologists, medical humanists, architectural historians, or anthropologists can certainly contribute to the study of this critical issue as well. The Natural Sciences focus on the physical dimension as the primary agent or entity. The Humanities are deeply engaged with the curious phenomenon we call the 'human being' in its spiritual qualities, in its social and economic interaction with other people and the natural environment, and all this constitutes the starting point for the dialogue between the traditional Humanities and all the other fields if they want to join the effort to examine human life through a variety of lenses.

We do not argue for a silly leveling of the significant scholarly and scientific differences in order to be an all-inclusive research field. Differences will always remain, and they are certainly appreciated and necessary. But just as in a Venn-diagram, our journal is trying to reach out to many neighboring disciplines and to establish a shared space for them all because we believe that there are common concerns and desires. We as human beings are in desperate need for this new kind of discourse, especially since we now live in the Anthropocene, and Humanities wants to serve as the critical platform where this innovative discourse can take place. Literary texts can harmoniously complement visual documents, musical compositions, architectural designs, computer games, and so forth, as long as one and the same concern remains in our focus, the human spirit. Little surprise that the medical humanities and architectural humanities, among other branches, can learn deeply from literary and artistic expressions and vice versa in order to help humanity to overcome endless divisions and the dangerous process of atomization of human life. As the ancient Romans already formulated so well, mens sana in corpore sano.

(C) 2020 by the author. Licensee MDPI, Basel, Switzerland. This article is an open access article distributed under the terms and conditions of the Creative Commons Attribution (CC BY) license (http://creativecommons.org/licenses/by/4.0/). 